\begin{tabular}{|l|l|l|l|l|l|}
\hline MUNIBE Antropologia-Arkeologia & $n^{\circ} 66$ & $245-258$ & DONOSTIA & 2015 & ISSN 1132-2217 • eISSN 2172-4555 \\
\hline
\end{tabular}

\title{
Análisis del sistema defensivo y del uso del espacio intramuros de un poblado fortificado: el Castro de Pendia (Boal, Asturias) entre la Edad del Hierro y la Época Romana
}

\author{
Analysis of the defensive system and the use of space inside a hillfort: the exam- \\ ple of Pendia (Boal, Asturias), between the Iron and the Roman Age
}

PALABRAS CLAVES: Murallas, ${ }^{14} \mathrm{C}$, NW de la PI, análisis espacial, monumentalidad.

GAKO-HITZAK: Defences, ${ }^{14} \mathrm{C}$, NW of Iberian peninsula, Spatial analysis, Monumentality.

KEY WORDS: Harresiak, ${ }^{14} \mathrm{C}$, NW de la PI, espazioaren azterketa, monumentaltasuna.

Fernando RODRÍGUEZ DEL CUETO(1)

\section{RESUMEN}

La muralla ha constituido un elemento esencial en el estudio de los recintos fortificados del ámbito protohistórico, relevancia que propició que se le fueran añadiendo otros roles a las cercas aparte de su ya innegable utilidad como elemento protector. El castro de Pendia siempre se incluyó dentro de los recintos de pequeñas dimensiones fuertemente protegidos, clasificación que se vio ratificada en análisis recientes del espacio intramuros que aquí presentamos. Así, en este castro tanto defensas como edificios rituales ocuparon una extensión de terreno a considerar, que llegó a superar incluso los metros cuadrados destinados al espacio doméstico. Por esa razón quizá debamos valorar ciertos castros no solo como enclaves estratégicos que permitieron la subsistencia o la defensa, puesto que es probable que algunos de ellos pudieran ser además lugares con otras muchas funciones para las comunidades protohistóricas, acentuando así los valores polisémicos que seguramente tuvieron muchas de estas aldeas protohistóricas.

\section{LABURPENA}

Harresia oinarrizko elementua izan da esparru protohistorikoko barruti gotortuak aztertzeko garaian. Garrantzi hura zela eta, hesiei beste rol batzuk gehitu zizkieten elementu babesle gisa betetzen zuten erabilgarritasun ukaezinaz gain. Pendiako kastroa beti sartu izan da gogor babestutako neurri txikiko barrutien barruan. Gainera, hemen aurkezten dugun harresi-barruko espazioaren inguruan duela gutxi egin diren azterketek berretsi egin dute sailkapen hori. Kastro honetan, defentsek zein erritu-eraikinek lur-hedapen esanguratsua okupatu zuten. Etxeko espaziora bideratutako metro koadro kopurua ere gainditu zuen gainera. Hori dela eta, agian kastro batzuk ez genituzke iraupena edo defentsa ahalbidetu zuten kokaleku estrategiko gisa soilik baloratu beharko. Izan ere, litekeena da haietako batzuk, gainera, komunitate protohistorikoetarako beste hainbat funtzio betetzen zuten tokiak izatea. Horrek, era berean, seguru asko herrixka protohistoriko haietako askok izandako balio polisemikoak areagotuko ditu.

\section{ABSTRACT}

The fortifications had been a key point for scholars of the Iron Age in Europe and their importance has moved over time to the studies about architecture and urban development. As a consequence other roles were added to the defensive aspects that used to characterize these structures. Thus fortifications can be consider for example as symbols of communities due to the enormous efforts that were behind the construction of these structures.

In the particular case of Pendia a brief summary of the defensive remains were developed. But unfortunately only some of them had been researched and related with radiocarbon dates. The broad extension of the fortifications and their special features demand big efforts and resources that couldn't be assumed in the terms of Navia's Valley project. Nevertheless four dates are related with different stages of eastern wall dating their construction.

Given this situation a spatial analysis of the hillfort was carried out trying to discern the amount of space related with the fortifications and the room linked with other uses. Based on this study it may be possible to propose that defences in Pendia prevail over the rest or, at least, they take up significant percentages. For instance, defences and ritual buildings (the saunas and the assembly houses) occupied even more room than the square meters destined to domestic space. After comparing this case with other hillforts of our area the figures are even more remarkable and underlined the peculiarity of Pendia. Nevertheless this hillfort it was not a unique case and their distinctive features can be the result of the lack of research in this kind of small hillforts. Because in western part of Asturias, for example, there are several examples of hillforts with close parameters to Pendia in position, extension and fortifications but none of them was researched.

As a result these hillforts does not seem individual entities but villages involved with their surroundings and with other communities. Only from the collaboration between different groups enormous fortifications can be understood in the small hillforts. Because groups of few families always have their limits when they have to assume big efforts. For this reason it is necessary see some hillforts not only as strategic points that gave sus-

(1) Profesor Asociado. Universidad de Oviedo. Departamento de Historia, Área de Prehistoria. Facultad de Filosofía y letras, Campus del Milán. c/ Teniente Alfonso Martínez, s/n, 33011, Oviedo, Asturias. email: rodriguezcfernando@gmail.com 
tenance or protection to the community: a few of them could have had other functions. The polysemic significance of the hillforts explains therefore the attention developed in some places to not domestic spaces, stressing the huge diversity of Iron Age villages.

Only the conquest by Rome changed the previous situation, in which links between the Iron Age communities tied the relations in different aspects of their lives (the defences between them). The new society that arose, new patterns, or new authorities could be reasons to explain the significant changes that will characterize the new times.

\section{1.- EL DEBATE ACERCA DE LAS DEFENSAS PROTOHISTÓRICAS. NUEVAS LECTURAS}

Uno de los aspectos que más se han remarcado dentro de los estudios protohistóricos ha sido el de las connotaciones militares que tenían murallas y otros elementos defensivos; sin embargo, las fortificaciones de la Edad del Hierro han generado en las últimas décadas una variada literatura científica que ha permitido ir renovando en gran medida las explicaciones tradicionales. En este sentido, y tras el estudio de varios recintos fortificados de época prerromana y romana en la zona de la Cabrera leonesa y en el entorno de las Médulas, Fernández-Posse y Sánchez Palencia, hicieron hincapié en el papel que pudo tener la muralla como un elemento que da cohesión interior y exterior a la comunidad que la está construyendo, ayudando a sentar las bases de la organización interna del propio hábitat fortificado (SÁNCHEZ Y FERNÁNDEZ-POSSE, 1985; FERNÁNDEZ-POSSE Y FERNÁNDEZ, 2000: 88). Dentro de esa misma línea de argumentación y trabajo se otorgó también a los muros defensivos un papel que los coloca como gran símbolo de la ambivalencia de las relaciones intergrupales castreñas. De esta forma, aunque la cerca podría reflejar la necesidad de aislamiento y la existencia de posibles conflictos entre las comunidades, entre esos grupos fueron necesarios también intercambios así como una cierta exogamia que permitiera la supervivencia biológica del colectivo (SASTRE, 2001: 65).

La propia capacidad defensiva de los recintos fortificados también ha sido muy matizada recientemente por algunos autores ya que si bien las murallas son «monumentos innegables dentro de lo castreño, la capacidad real de defensa o de estancia prolongada en un sitio dentro de estos perímetros cercados debió ser francamente corta» (VILLA, 2008b: 702). Quizá eso haya animado a los investigadores a buscar otras explicaciones diferentes a la ya manida visión defensiva, llegándose a la conclusión de que las cercas pudieron tener también una importante consideración como referente de la comunidad o de la ciudad que las erige. Por ese motivo algunos autores destacaron los valores simbólicos de las mismas para otros ambientes protohistóricos, apoyándose en las reflexiones que ya pusieron por escrito en su momento algunos filósofos clásicos: en concreto Platón que, en las Leyes, reflexionará acerca de cómo la decadencia de una muralla es un símbolo del mal estado o del mal funcionamiento de las instituciones de la ciudad a la que cobija (GRACIA, 2006: 120). Por tanto, esa impronta defensiva se pudo mezclar con una relevancia simbólica destacada ya desde los tiempos protohistóricos, enfoque válido también para ejemplos posteriores puesto que esa misma polisemia de la fortificación continua presente en las medievales, tal y como recuerdan las propias Partidas de Alfonso X (CAMINO, 2002: 151).

Además las murallas no solo recibieron un tratamiento individualizado en la historiografía, sino que su estudio se integró también en los modelos sociales propuestos para las comunidades castreñas. Así ocurrió por ejemplo en la síntesis llevada a cabo recientemente por G. Ruibal ya que su resumen de los planteamientos actuales condensa muy bien todos los parámetros que, a nuestro modo de ver las cosas, pudo suponer la construcción de las fortificaciones (GONZÁLEZ, 2008: 909). En ella integra desde los factores económicos, sociales, o simbólicos de los emplazamientos protohistóricos (y por ende, de sus defensas), sin descargar de contenido militar a estos. De este modo, y siguiendo a Ruibal, la existencia de estos elementos protectores no tendría por qué ser vista como resultado de contiendas bélicas habituales, sino que podría manifestar únicamente el desvelo puesto en erigir elementos disuasorios frente a amenazas de cualquier tipo (op. cit., 904).

Este planteamiento es muy semejante a los que se desarrollaron en el ámbito británico donde, ante la complejidad de los registros arqueológicos defensivos, se afrontó el análisis de las fortificaciones con suma prudencia y con una cierta amplitud de miras. Nos estamos refiriendo en concreto a los enfoques propuestos por Ralston para la zona atlántica, que le llevaron a defender que en ningún caso se pueden establecer explicaciones simples o sencillas para estos fenómenos, puesto que la construcción y mantenimiento de las defensas pudo estar seguramente asociada a complejos procesos socio-políticos dentro de las comunidades protohistóricas (2007: 114). Estas reflexiones parten de las estimaciones sobre la cantidad de trabajo y de esfuerzo que supondría levantar estas estructuras, una cuestión que también ha polarizado las interpretaciones en el noroeste hispano: desde aquellos que han rebajado mucho la carga de estas obras (FERNÁNDEZ-POSSE Y FERNÁNDEZ, 2000: 107; CAMINO, 1995: 163)', a los que mantienen la importancia de esas tareas y el compromiso a largo plazo que debieron suponer (TORRES, 2005: 202). En todo caso, incluso en los cálculos más bajos el período mínimo para tener lista una fortificación supondría de medio año a un año. Cifras muy próximas, en sus valoraciones más altas, al cálculo de catorce meses realizado por Chapa y Mayoral para la construcción de las defensas de algunos poblados fortificados ibéricos, como la Bastida de Mogente (2007: 103).

Desde luego el debate tiene difícil solución en la actualidad, más aún si consideramos los trabajos de construcción y mantenimiento de una forma conjunta, porque lo que sí reflejan los registros es la constante modificación de los parámetros defensivos según avanza el tiempo, así 
como un continuo desvelo por la reparación de las fallas producidas en los cercados. Un hecho bien constatado en algunos cinturones defensivos de largo recorrido como, por ejemplo, el Chao Samartín (VILLA, 2002:177), o en todos aquellos que ven renovada su protección con las murallas compartimentadas o de módulos (CAMINO, 2000). Quizá la mayor dificultad estriba, por tanto, en que muchos de esos debates resultan complejos de dirimir actualmente; al menos, con la información disponible y quizá únicamente mediante el desarrollo de la arqueología experimental aplicada a estos campos, ámbito en el que ya se han hecho importantes estudios (EVANS Y LIMBREY, 1974; RALSTON, 2006: 99), se pueda empezar a paliar el déficit de conocimiento que tenemos acerca de qué supuso en términos de esfuerzo y trabajo crear estas estructuras en época protohistórica. En definitiva, sean obras con una intensidad o con otra, lo que es innegable es su importante papel para la comunidad y la pervivencia del mismo en el tiempo.

Otra cuestión bien diferente es quién se encargó de construirlas, ante lo cual se ha llegado a plantear un modelo de colaboración como parte de pactos o ataduras de tipo social o político que podrían motivar que la gente participase en la creación de las defensas (op.cit:: 100). En cuanto a la parte técnica, si bien muchas de las obras presuponen, ante su calado y dificultad, la existencia de una serie de constructores-arquitectos en cada uno de estos lugares, no hay testimonios evidentes de este tipo de trabajadores al menos en la Europa templada (ibídem).
En términos generales, el registro del noroeste resulta menos explícito que el de otros recintos fortificados del territorio europeo. Por ejemplo, en los hillforts de las islas británicas han aparecido, asociados a contextos defensivos, desde lingotes de hierro a restos humanos o animales (RALSTON, 2006: 117-121; 2007: 123). Hallazgos que sin duda demuestran cómo, tras los fines más «prosaicos» de las fortificaciones, se pueden esconder otros más complejos de desentrañar, y que podrían cargar de connotaciones de tipo ritual o simbólico estas estructuras (op. cit., 128). No hay duda que estos fenómenos son menos frecuentes en los poblados fortificados del noroeste, como bien apunta Ruibal (GONZÁLEZ, 2008: 915); aun así, aspectos como el funerario empiezan a hacer tímida aparición en la protohistoria regional y peninsular, tal y como demuestra la aparición de una calota craneal de una mujer en la entrada al recinto fortificado más antiguo del Chao Samartín (VILLA Y CABO, 2003).

\section{2.- EL CASTRO DE PENDIA: DATOS GENERALES Y EMPLAZAMIENTO}

El castro de Pendia (Figura 1) fue excavado por primera vez por parte de A. García y Bellido (1942), y la publicación de sus resultados alcanzó, gracias al prestigio del autor y de la revista Archivo Español de Arqueología, repercusión nacional e internacional. No obstante, hasta el año 1999 no se vuelven a retomar las excavaciones en

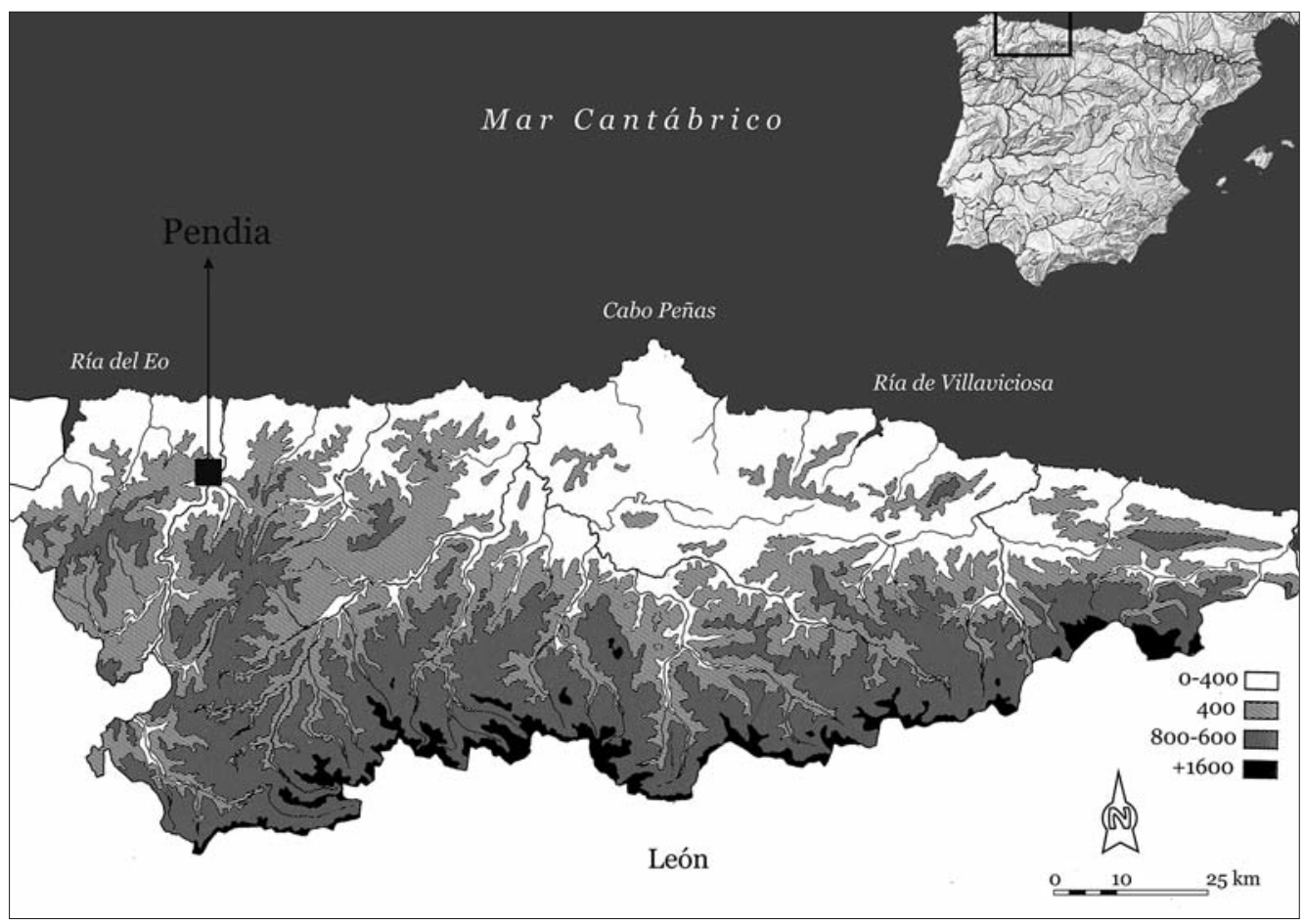

Fig. 1. Ubicación general del castro de Pendia (Boal, Asturias) / Situation of the hillfort of Pendia (Boal, Asturias)

${ }_{1}$ Sobre los datos extraídos en Borrenes, Fernández-Posse estimó que un grupo de diez a veinte personas podría construir la muralla en un período de entre cinco y diez meses. 
el yacimiento, como consecuencia de la restauración de las dos saunas castreñas presentes intramuros (VILLA, 2007). Esas primeras labores tendrán continuidad a partir del año 2003, momento en el que se inicia una serie de ocho campañas estivales que, con sus discontinuidades, se prolongarán hasta el año 2013. Los objetivos esenciales de estas intervenciones eran la recuperación de muchos sectores del yacimiento severamente afectados por la exposición a la intemperie durante décadas de las estructuras exhumadas, situación propiciada por la desidia institucional y arqueológica en la que se sumió al yacimiento. La renovación de la dirección arqueológica del Plan Director de la Comarca (1999) supondría un punto de inflexión clave, porque partir de ese momento se comenzará a recuperar mucha información en Pendia, compatibilizando siempre las tareas de restauración con la investigación de un sitio del que apenas si había datos: solo podíamos contar con el informe de García y Bellido y con el estudio de los materiales realizado por J. L. Maya (1988). De esta forma se fueron recogiendo, campaña a campaña, pequeños retazos de la historia de este recinto que, desde el año 2009, están siendo dados a conocer en diversas publicaciones (RODRíGUEZ Y VILLA, 2009; 2013; RODRÍGUEZ, 2012, 2013) a las que hemos de sumar una tesis doctoral defendida recientemente ${ }^{2}$. En la actualidad, las fechas más antiguas recuperadas indican la ocupación desde al menos la II Edad del Hierro, continuando el castro habitado hasta el siglo II d. C.

En lo que respecta al patrón de emplazamiento y fortificación que se deduce de Pendia (Figura 2) los rasgos que conocemos actualmente encajan bien en la propuesta de Parcero para los castros de la II Edad del Hierro, tanto en lo que atañe a lo defensivo como para la preparación de los lugares previamente a la edificación (PARCERO, 2005: 16). Según este, durante la segunda fase de la Edad del Hierro del Noroeste se incrementa la fortificación y los grupos humanos se llegan a asentar en emplazamientos menos obvios o relevantes en cuanto a su visibilidad que los del Hierro I, debido a una mayor ocupación del espacio y a un mayor conocimiento de las técnicas para el aprovechamiento de todo tipo de suelos (op. cit: 18). Los casos de la ría de Villaviciosa (CAMINO, 2002: 142), o de

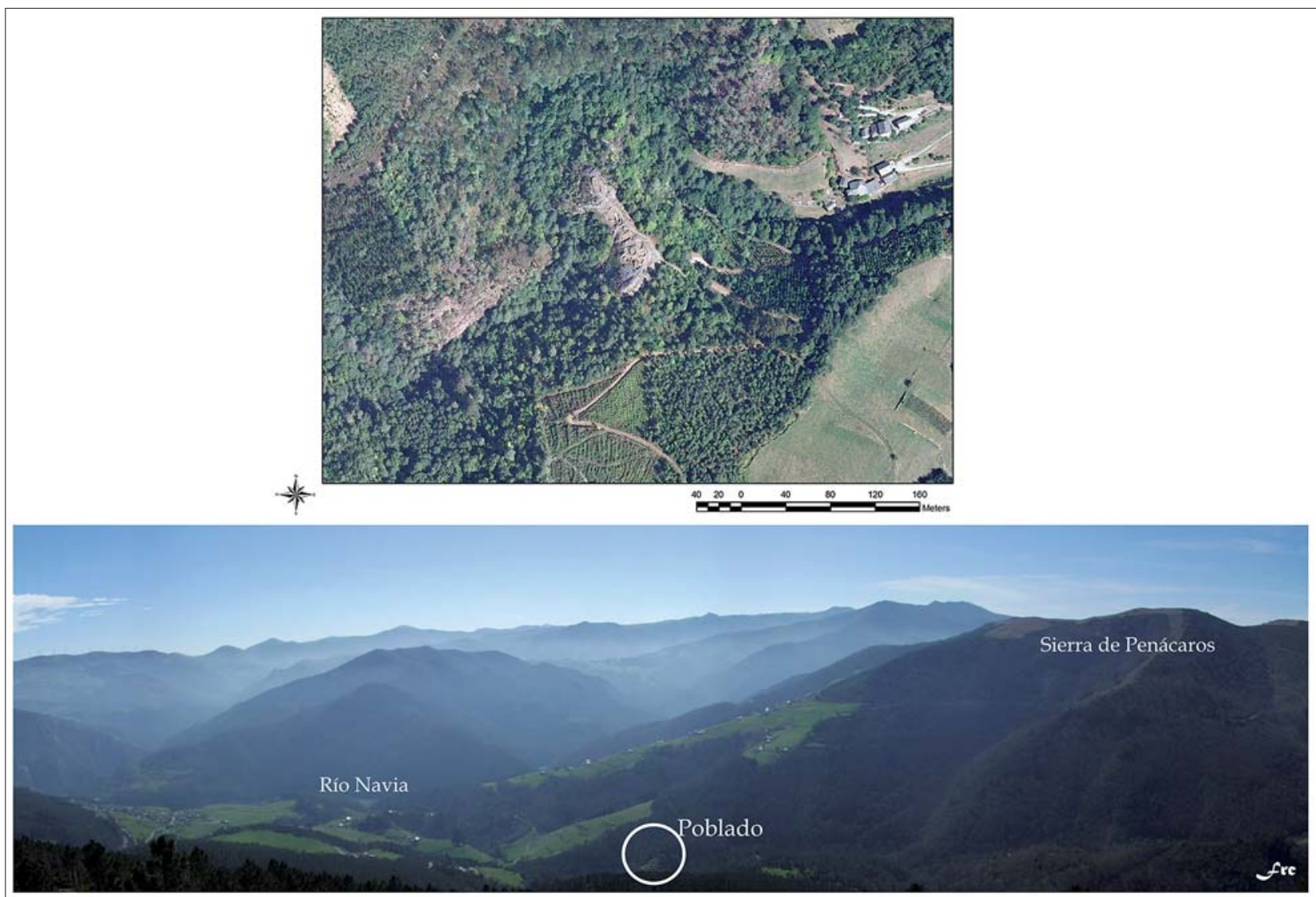

Fig. 2. Vistas en ortofoto de la posición del poblado (arriba),y una panorámica en relación a montañas, ríos y zonas de cultivo (abajo) / Position of the hillfort (up) and a panoramic view in relation with mountains, rivers and possible crops (down).

${ }^{2}$ Arquitectura, urbanismo y espacios domésticas: su evolución en el castro de Pendia un recinto fortificado del occidente de Asturias (S. IV a. C.- S. I/ d.C.), Tesis doctoral inédita con Mención Internacional, defendida en la Universidad de Oviedo por Fernando Rodríguez del Cueto el 10 de marzo de 2015. 
los estudios pioneros en la península realizados en los años ochenta para algunas comarcas aragonesas ya reseñados por Camino (RUIZ Y FERNÁNDEZ, 1984: 47), junto a alguna referencia más del ámbito vetón que conduce al mismo modelo (MARTíN, 2004: 127) remarcan la validez de la propuesta de Parcero. No obstante estos parámetros son útiles ahora, pero el castro de Pendia no se ha sondeado con la suficiente profundidad como para fijar su cronología inicial; cualquier tipo de envejecimiento de esta, modificaría el manso encaje que existe en el castro boalés entre estas pautas de emplazamiento y las cronologías a las que se asocian. Algo que además parece plausible, puesto que las realidades documentadas no tienen por qué convertirse en esquemas uniformes o únicos, válidos para amplios territorios, ni tampoco deben encajar siempre en otros espacios diferentes a los considerados en cada propuesta particular.

Ya desde época prehistórica se comprueba la generosa variabilidad que existe a la hora de elegir sitios para vivir, sensación que se incrementa cuando nos movemos a sectores diferentes a los más estudiados, quizá porque en el fondo no es más que un rasgo consustancial a las propias formas de ocupar el espacio por parte de los pueblos (GONZÁLEZ, 2006-2007: 178). Por lo demás, y siguiendo con el modelo de Parcero, será durante las fases medias y finales de la Edad del Hierro cuando los poblados se amplíen y se empiecen a modificar los cerros para adaptar éstos a la ocupación (2005: 18), rasgo que también encaja con la información aportada hasta el momento por Pendia.

No podemos olvidar tampoco que hay razones fundadas para creer que, al margen de cuáles sean las fechas más antiguas del yacimiento, este patrón percibido en Pendia de asentarse en lugares bajos, con poco espacio disponible (alrededor de media hectárea), y que se caracterizan por un terreno marcadamente irregular es común a muchos otros sitios de esta comarca o de la península ibérica, tal y como ya hemos remarcado con anterioridad (ver nota 2 ).

\section{3.- LA MURALLA ORIENTAL DEL CASERÍO SUR: RESUMEN DE LA SECUENCIA}

No hay duda que las murallas de Pendia, que circundan la gran mayoría de su perímetro, junto con los dos fosos que protegen el flanco meridional y el imponente torreón que remata este punto, siempre dieron la apariencia de fortín a esta pequeña aldea castreña (Figura 3). No obstante, aunque las diferentes partes del entramado defensivo sean del mayor interés, solo se han podido sondear tramos muy concretos de la cerca que protegió el caserío sur y por ese motivo queda por conocer todavía cuál es la relación de esta zona sur con las defensas y el recinto septentrional, aunque esperemos que en un futuro se puedan ir resolviendo las dudas acerca de las cronologías de ambos cercados.

En la actualidad, por tanto, la descripción se ciñe a lo que buena parte de los recorridos nos permiten ver de visu, sin que haya otra información que facilite ahondar en más detalles. El recinto norte, por ejemplo, muestra una muralla lineal de entre dos y dos metros y medio de anchura, cuyo recorrido parece adaptarse a las irregularidades del terreno facilitando extender el espacio de uso del poblado el mayor número de metros posibles. Por ese motivo, los puntos en los que hay abruptos cantiles sobre el cauce del arroyo, son los que sirven para determinar el límite en la gran mayoría de las ocasiones. Destacan sobremanera algunos puntos como la entrada que fue reforzada gracias a dos bastiones semicirculares, siendo de especial porte el del lado oriental del paso. Si bien en algunas partes del entramado defensivo hemos documentado varias líneas de fortificación, no parece ser este el caso del recinto norte. Por último, hemos de decir que muchos de los elementos ya han sufrido corrimientos y roturas en sus lienzos, lo que aconsejaría plantearse ir resolviendo sus principales deficiencias en un futuro.

El resto de los elementos defensivos parecen incorporarse y abrazar al recinto septentrional, aunque esta lectura preliminar desde luego debe ser confirmada mediante la datación de tramos diferenciados del entramado defensivo para llegar a conclusiones definitivas sobre la evolución del poblado y sus cercados. De cualquier forma los fosos y la gran torre al sur suponen unas defensas claves para la protección del flanco más vulnerable y justifican la proliferación de elementos en este espacio. La planta del torreón meridional ya fue definida como ovalada por García y Bellido en sus dibujos y los recorridos visibles parecen confirmar esa impresión preliminar. La existencia de varias líneas por debajo de la cúspide, podrían marcar además la imperiosa necesidad de reforzar una estructura de unas proporciones muy considerables. Su construcción en seco y la entidad del aparejo desperdigado por doquier en el entorno del yacimiento manifiestan el alcance que debió tener esa obra en su momento. Aquí también se partía, como en el resto de las defensas, del inconveniente de no tener superficies claras de asiento, impedimento que quizá aquí es aún más considerable, sobre todo si ponderamos la inclinación actual; por eso la proximidad de la posible cantera, el foso, pudo ser un atenuante a la hora de desarrollar el trabajo. Además hay una sintonía clara entre el torreón y la muralla, patente gracias a algunos sectores donde ambos conectan, mientras los restos de la cerca a ambos costados del asentamiento parecen cerrar un perímetro que, en todos los casos, ha de jugar con los inconvenientes de construir en ladera. Aunque buena parte del flanco oriental del cercado posiblemente sucumba ante estructuras domésticas posteriores, el tramo occidental conservó en superficie un mayor número de elementos a pesar de la plausible desaparición de otros muchos. En suma, todos los sectores que se conservaron de la muralla, en superficie u ocultos, demuestran la pericia de los constructores, que se aprovechan claramente de las estructuras dejadas a la vista o de aquellas que dejaron enterradas para que contengan los materiales de relleno de nuevas terrazas.

Los tramos sondeados sí que permiten proponer con seguridad que el caserío sur estuvo protegido por un muralla lineal que se remonta, al menos, al siglo IV a. C. y que 


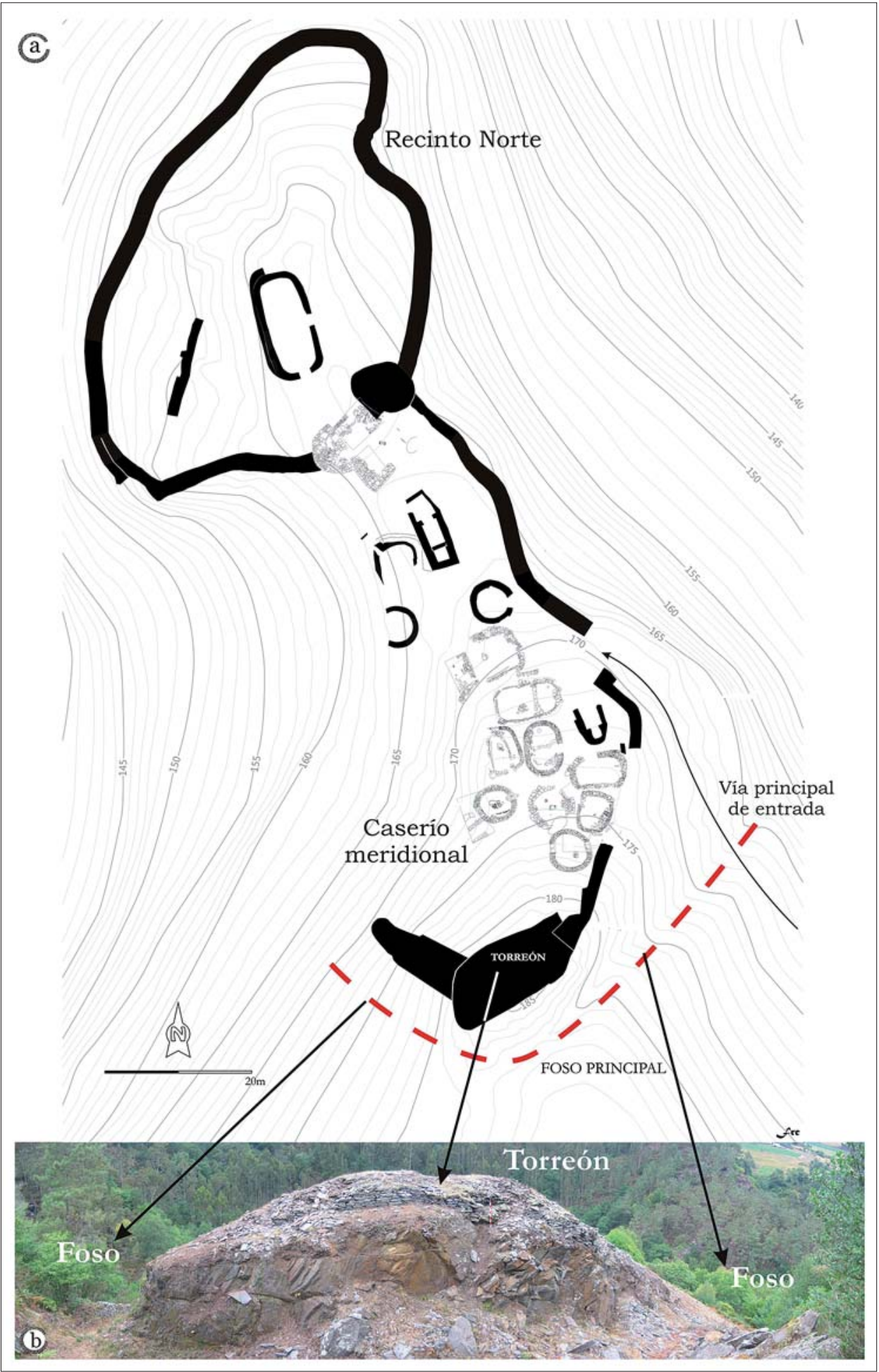

Fig. 3. a) Planta, con indicación en gris de los espacios excavados (2003-2013) b) Foso y torreón en la zona meridional / a) Drawing of the hillfort. In grey colour the digging areas between 2003-2013. b) Ditch and tower in the southern part. como buena parte de las murallas de este tiempo sufrió refuerzos y distintas reparaciones entre los siglos II y I a. C., cronología bien aquilatada por cuatro fechas AMS que afectan a esta área específica. Toda esta secuencia ya ha sido publicada (RODRÍGUEZ Y VILLA, 2009) y también ha sido recogida, de una forma resumida, en nuestra tesis doctoral (vid. supra). Las adendas a la muralla documentadas supusieron la agregación de muros de refuerzo por la cara interna de la muralla, quizá para paliar las carencias de firme de algunos tramos del muro aunque no debamos descartar que pudiesen servir también de plataforma de acceso a la zona superior de la defensa. Lo que es evi- 
dente es que con este proceso pierden metros domésticos que son empleados para remendar posibles deficiencias del perímetro; curiosamente, el fenómeno es a la inversa durante los tiempos romanos donde las casas ganan la batalla claramente a una muralla que ya se ha visto desprovista de buena parte de su importancia. Quizá por eso se puede plantear que la relación de los habitantes del poblado con la cerca cambia por completo tras la conquista romana, puesto que se está transformando Pendia en un espacio abierto en el que se aprovecha esta como contención de escombro, apoyo de nuevos edificios o de plataforma para el nuevo callejero (Figura 4).

En definitiva, y detrás de esta dilatada secuencia constructiva, parece percibirse una constante preocupación, al menos hasta el siglo II-I a. C., por los elementos defensivos puesto que, si no hubiera sido así, estos no habrían siquiera pervivido a la época romana. Y parece ser que muchos de ellos, aunque seguramente muy trastocados ya, estuvieron presentes todavía en los períodos postreros del poblado. La muralla en Pendia aparece recortada en su trazado y del torreón meridional tenemos datos muy escasos puesto que todavía no ha sido excavado, pero bien sea en pie o en un estado de ruina parcial y progresiva debió estar presente en los últimos períodos de habitación, de forma muy semejante a lo que pudo ocurrir también con la sauna más antigua de Pendia.

Por descontado, al hilo de toda esa información van surgiendo una serie de preguntas muy sugerentes aún sin respuesta en buena parte de los casos: qué suponen estas variaciones para la comunidad, cómo se explican, cuáles fueron los motores de la transformación, si se trató de un cambio intenso en el modo de ver el poblado y de habitarlo o si, al contrario, fue una mutación mucho más leve de lo que solemos pensar. Para ver el alcance de esa trascendencia, trataremos de abordar el análisis espacial del sector intramuros de Pendia en los próximos epígrafes de este trabajo, de modo que podamos evaluar qué valor tuvieron una serie de elementos que ocupan un terreno considerable en el castro y que parecen definitorios o esenciales en el mismo.

\section{4.- EL USO DEL ESPACIO INTRAMUROS EN PEN- DIA: ANÁLISIS DE SUS PROPORCIONES}

En el caso de las obras defensivas de Pendia estamos ante un conjunto de creaciones que alcanzan unas dimensiones muy llamativas y, hasta cierto punto, desmedidas. Este rasgo ya lo había destacado Maya en su tesis doctoral, extrañado ante la desproporción entre el complejo defensivo y el espacio habitado que este cercaba (1988: 41), lectura que nos parece acertada y que llevó a este arqueólogo a definir Pendia como poblado enigmático. Si bien es cierto que este entramado dispar pudo haber sido hecho en distintos momentos de la ocupación, y ser el resultado de las necesidades de cada uno de los períodos, no hay duda que existió una preocupación destacada por las fortificaciones. Esto representa una realidad, al margen de la posible eficacia protectora que este conjunto de obras hayan podido tener en su momento, y dejando de lado también si se deben a una necesidad acuciante fruto de las tensiones entre las comunidades, ante un sencillo intento

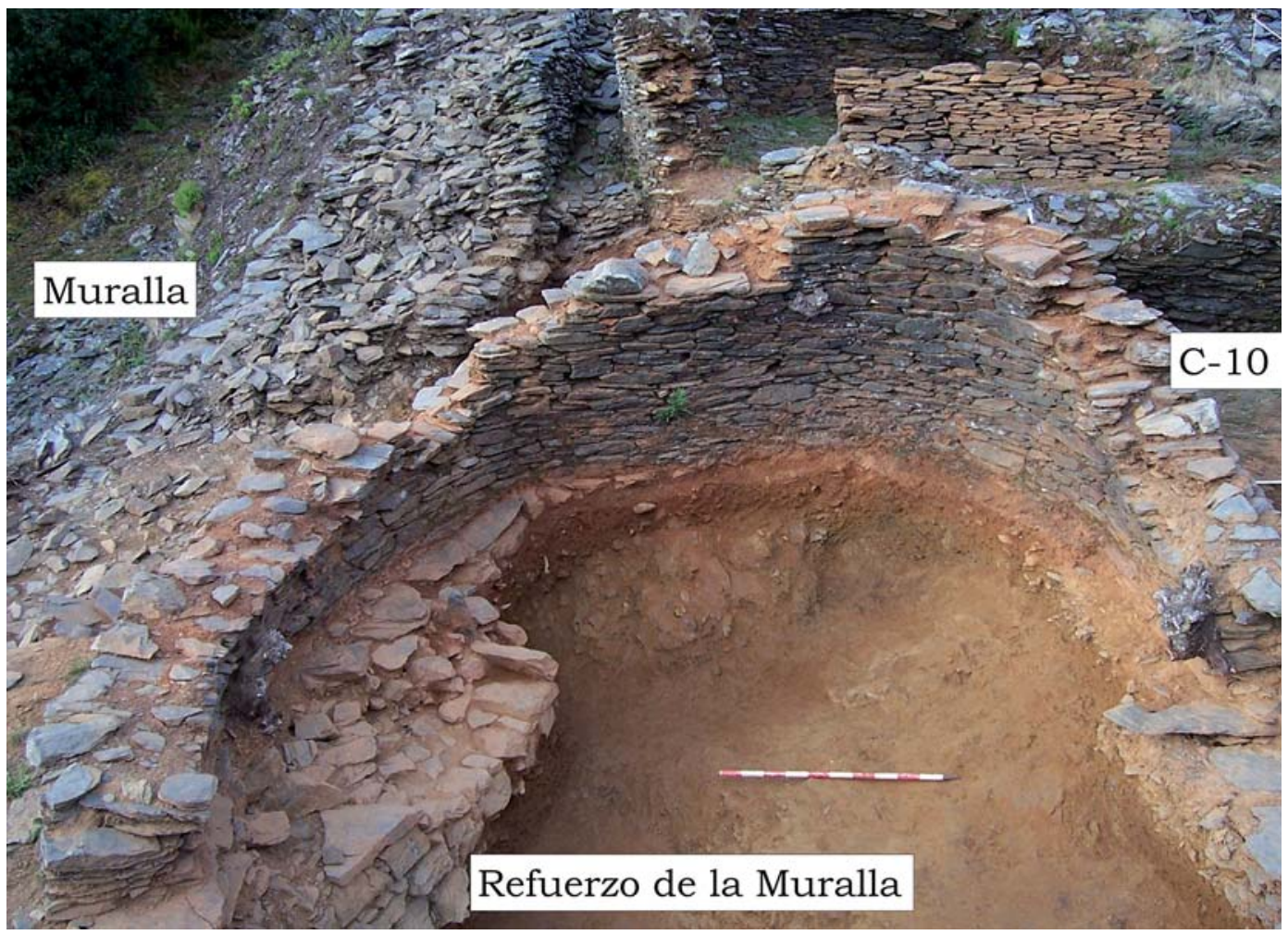

Fig. 4. Relación de las defensas con las construcciones domésticas en el caserío meriodional (construcción diez) ( Links between defences and domestic spaces in the southern part of the hillfort (building number ten). 
de ratificar la posesión del lugar, o a una combinación de ambas motivaciones.

Así, y para poder darle una explicación a las apreciaciones todavía irresolutas planteadas por Maya para el castro boalés, desarrollamos una medición precisa de cómo se reparte el espacio total del poblado, trabajo que proporcionó cifras muy significativas. En otros términos, vamos a estudiar no solo la distribución de la casi media hectárea que ocupa (4950 $\mathrm{m}^{2}$ aproximadamente), sino también las relaciones que, grosso modo, existen entre los principales grupos funcionales del recinto. Es evidente, que el análisis parte de una dificultad evidente: el caserío analizado es el palimpsesto de siglos de utilización del sitio y se corresponde principalmente con los últimos momentos de ocupación romanos por lo que siempre resulta más complejo analizar la parte indígena con detalle, ya que la superposición de elementos más modernos enturbia la lectura de las estructuras pretéritas. De todos modos, aunque nos veamos obligados a ponderar sobre todo el grupo de edificios de época romana, la pervivencia de ciertos elementos antiguos hace aún más válido e interesante el análisis; mucho más cuando las estructuras que parecen subsistir en mejor estado son las defensivas o las saunas.

La división ha procurado ser lo más sencilla posible considerando etiquetas genéricas bien diferenciadas unas de otras en su uso y, para ello, se han dividido los espacios defensivos y rituales de aquellos que no lo son ${ }^{3}$. Así, mientras que de un lado tenemos a murallas, fosos, torreones o bastiones (defensivos) junto a las dos saunas y la casa de asamblea (rituales); del otro tendríamos edificios, calles y los restantes lugares del poblado. El resultado de la medición resulta sorprendente, pues indica que calles, edificios y espacios comunes, es decir los lugares donde almacenan, viven y transitan los miembros de la comunidad, tan solo ocupan 2224 metros cuadrados dentro del recinto interno de Pendia. Una cifra relativamente baja: el 45\% del terreno (Figura 5), mucho más si tenemos en cuenta que estamos hablando de una sociedad agropecuaria en la que el desarrollo de tareas en el campo y con el ganado, hubo de suponer un espacio mínimo en el que alojar aperos, grano u otros productos y quizá, ocasional o permanentemente, también dar cobijo a algunos animales (TORRES, 2005: 201).

El terreno restante (el 55\% del total), fue ocupado para otras tareas; algunas con una funcionalidad más evidente como son las murallas ${ }^{4}$ o las saunas, y otras como espacios de los que poco sabemos actualmente, como ocurre con el recinto norte5: un lugar con una entrada bien diferenciada, perímetro amurallado y solo una gran construcción sin que, en la actualidad, sepamos a ciencia cierta a

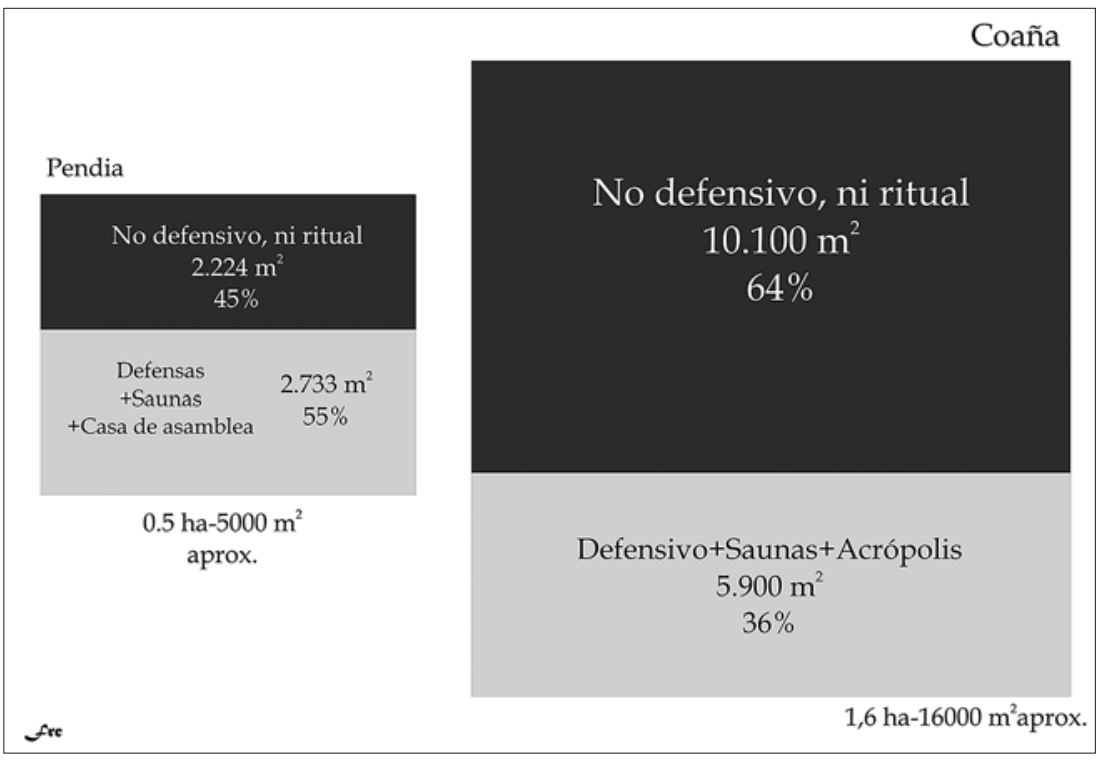

Fig. 56. Comparación entre el reparto del espacio interno de los castros de Coaña y Pendia / Distribution of the interior space in the hillforts of Coaña and Pendia.

\footnotetext{
${ }^{3}$ Si bien hemos de reconocer que se podrían hacer muchas divisiones intramuros, hemos elegido comparar la distribución e importancia de las arquitecturas defensivas con respecto al resto de estructuras arquitectónicas presentes, pues a nuestro entender ilustra el reparto francamente desigual de dos elementos capitales que están presentes tanto en Pendia como en todos los poblados fortificados. Además, si quisiéramos hacer estudios más detallados con otros parámetros (espacio doméstico, espacios de trabajo, etcétera) sería necesario contar con registros muy ilustrativos de estas actividades, información de la que por desgracia carecemos.

${ }^{4}$ Para verlo en números y que resulte quizá más ilustrativo, podríamos decir que el conjunto defensivo en sí (murallas y torreón), ocupa 1000 metros de los 4950 totales (Figura 6).

${ }^{5}$ No hay que descartar que las terrazas occidentales de esta parte del castro puedan deparar restos de ocupaciones domésticas en un futuro hecho que, obviamente, matizaría estas cifras. Por ese motivo resulta muy importante conocer qué ha ocurrido en esta parte del recinto y valorar la cronología de los posibles restos para determinar su alcance. En cualquier caso, el análisis superficial de estas terrazas parece establecer que se trata de una parte reducida dentro del recinto.

${ }^{6}$ Agradecemos las ideas y sugerencias aportadas por el profesor De Blas Cortina a la hora de confeccionar las figuras 5, 6 y 7 de este artículo.
} 
qué fue destinado el resto de este pequeño fortín intramuros. De todos modos, su importancia debió ser destacada, puesto que ocupó casi tanto como el resto del poblado habitado ¿A qué se destinaba entonces ese terreno? Contamos con poca información novedosa que permita responder a esa pregunta, al menos hasta que no haya otras exploraciones en el castro; lo único que podemos hacer es insistir en los rasgos esenciales de este lugar: un sitio muy amplio, muy bien defendido y, hasta el momento, con una única cabaña construida.

También quisimos comparar la información extraída en Pendia con la de otro sitio cercano, el castelón de Coaña7, para tener otro referente. Al tratarse de dos poblados con extensiones distintas (Coaña triplica la media hectárea de Pendia ${ }^{8}$ ), aunque con muchos elementos en común (ambos poseen un pequeño fortín bien diferenciado dentro de los límites amurallados, o dos edificios de sauna), el contraste nos parece que resulta apropiado y permite ponderar los resultados obtenidos en el castro boalés. Por ejemplo, el reparto del terreno no se produce de una forma semejante en los dos lugares: mientras que en Boal el espacio destinado a fines defensivos y rituales era muy extenso, no ocurre eso en Coaña, donde el llamado «barrio norte» junto a otros espacios (VILLA, 2013: 177) llegan a ocupar hasta el 64\% del sitio (Figura 6), quedando el 36\% restante destinado a otros fines: defensa, saunas y acrópolis. Por tanto, la distribución en el caso coañés parece bastante más coherente y equilibrada de la que apreciamos en Pendia y está también más acorde con las valoraciones realizadas para otros recintos protohistóricos peninsulares.

Al mismo tiempo, considerar la variable del espacio total que ocupa cada castro, nos permite estimar algunos aspectos relacionados con otros edificios destacados, como las saunas. Si bien tanto en Coaña como en Pendia hay dos edificios de baños, es posible que esa duplicidad no supusiese lo mismo para las dos comunidades (Figura 7). Por la sencilla razón que en Coaña hay $16000 \mathrm{~m}^{2}$ para construir y en Pendia, no se llega a los 5000, lo que traducido a porcentajes supone una ratio mayor en el caso boalés (puesto que es el 1.21\% del total) que en el coañés (que solo es el $0.83 \%$ del total disponible). Algo similar ocurre con las defensas, puesto que si bien las de Coaña parecen extenderse, grosso modo, por una mayor superficie de terreno (Figura 6), en términos porcentuales no se pueden equiparar tampoco. En Coaña supondrían únicamente un $12 \%$ del total actual del poblado, mientras que en Pendia se elevan hasta el 20\%.

Desde luego que Pendia tampoco es una excepción, pues en otros lugares de la Edad del Hierro peninsular se dan repartos del espacio muy semejantes a los observados en el castro boalés. Así parece ocurrir por ejemplo en los castros en la falda de los Montes de León, donde los recintos cuentan con menor superficie útil debido a que gran parte de los sitios han sido ocupados por las defensas (ORE-

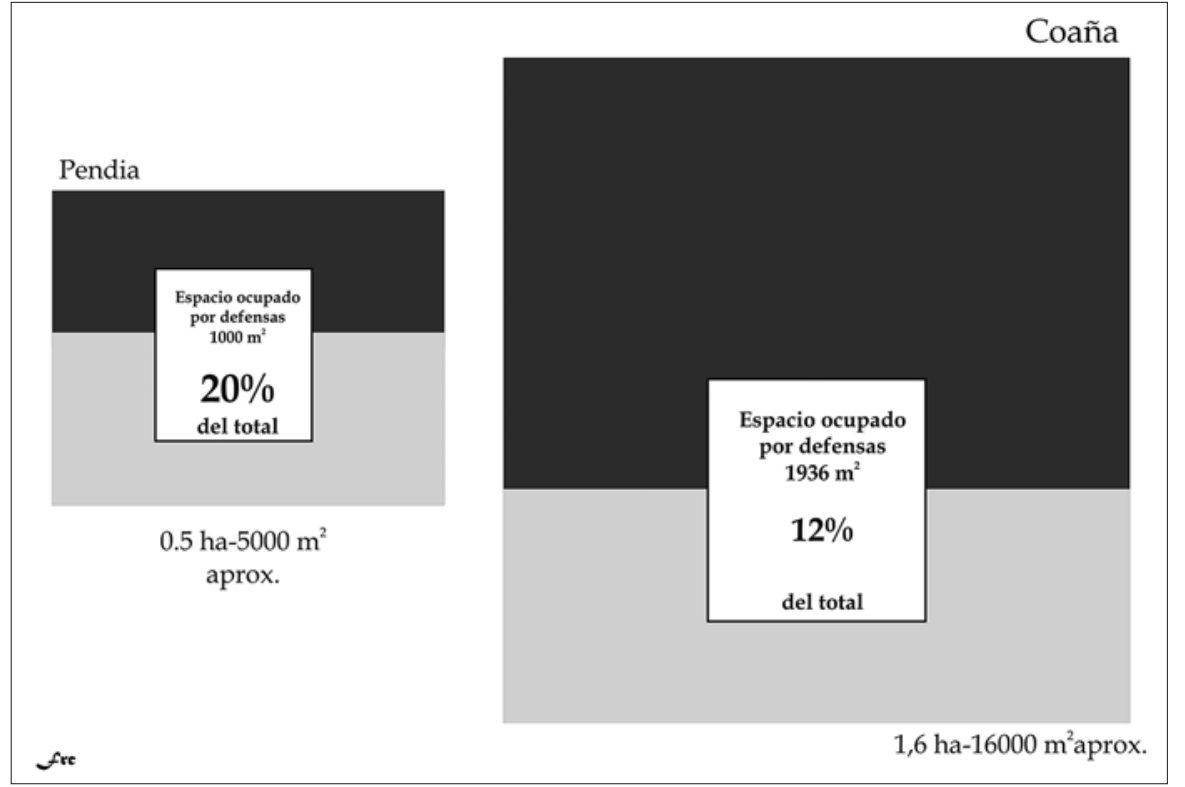

Fig. 6. Comparación entre la superficie ocupada por las defensas en los castros de Pendia y de Coaña / Area occupied by defences in the hillforts of Pendia and Coaña.

\footnotetext{
7 Si bien las mediciones de Pendia se pudieron realizar sobre la topografía informática del castro, donde las herramientas de Autocad y las precisas mediciones realizadas por E. Martín con estación total nos permitieron trabajar con mucha fiabilidad, para el caso de Coaña se utilizó la ortofotografía del Principado de Asturias descargada del IGN que, para esta labor, también resulta lo suficientemente precisa y explícita. ${ }^{8} \mathrm{Hemos}$ considerado únicamente los límites reconocidos o posibles del yacimiento que han sido publicados recientemente por Á. Villa (2013:177) que, según nuestras mediciones, no llegan a las dos hectáreas. Queda fuera por tanto el resto de la colina que, como nos indica este autor, se extiende hasta alcanzar las 7 ha. (2013: 175). Tampoco se ha considerado el llamado barrio «extramuros», sin ocupación probada hasta el momento. De todos modos, la adenda de nuevos espacios domésticos refrendaría aún más la interpretación y las lecturas hechas con los datos actuales, produciendo un contraste de números todavía más destacado.
} 


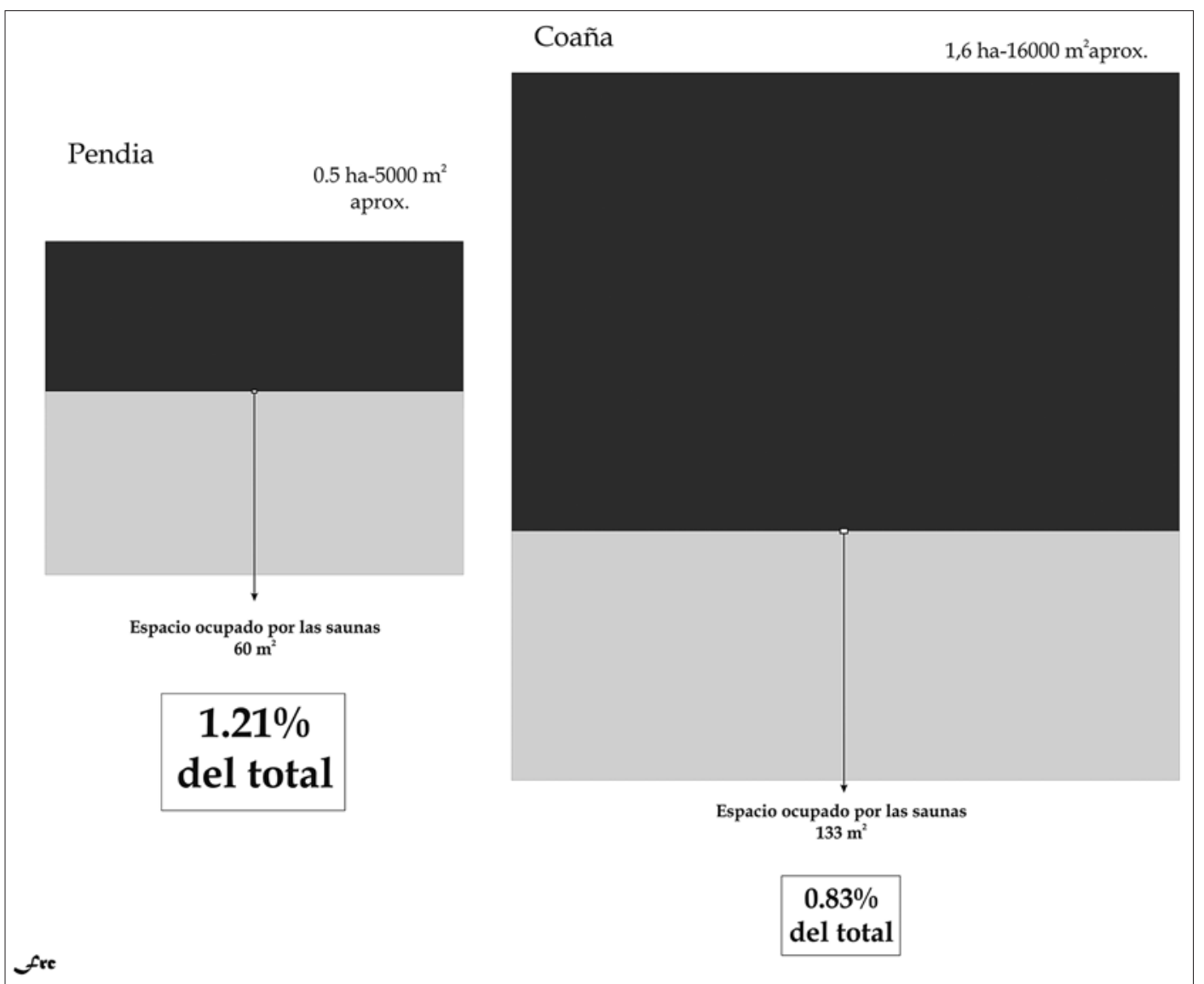

Fig. 7. Comparación entre la superficie ocupada por las defensas en los castros de Pendia y de Coaña / Area occupied by defences in the hillforts of Pendia and Coaña.
JAS, 1996: 61-70; ESPARZA, 2011: 26). Quizá que este tipo de fortificaciones norteñas también se podrían equiparar con las «pequeñas fortalezas» que Arenas Esteban aprecia en la zona del Alto Tajo-Alto Jalón, vinculadas además a explotaciones de carácter familiar. En todo caso, y al margen de los detalles y las estrictas semejanzas formales, lo que queremos destacar es que el fenómeno vuelve a parecer el mismo: posiciones muy defendidas, que debieron suponer una ingente cantidad de horas de trabajo para su construcción y mantenimiento y detrás de los cuales se esconden comunidades muy escasas que, en buena lógica, no podrían abarcar tales obras por sí solas como bien nos recuerda este autor (ARENAS, 2011: 141), peculiaridades que también apreciamos nosotros en el castro boalés.

Cifras aparte, lo que parece deducirse de esta información es el diferente reparto y peso que tuvieron arquitecturas y lugares concretos en los castros del occidente. No obstante el particular prorrateo del terreno apreciado en Pendia también se documentó en algunos hillforts del Reino Unido, tal y como ha reseñado Cunliffe (2006: 154), distribución que se podría explicar debido al significado que pudo tener cada uno de los poblados prehistóricos.
Así, lo que se construye en esas aldeas, arquitecturas o espacios, no se puede desligar en ningún momento de la comunidad que les da forma. Desde luego, la singularidad y el papel que durante su historia tuvieron cada uno de los núcleos castreños parece indicar una gama muy rica de funciones, roles o relevancias para las comunidades protohistóricas, de los que esos pequeños contrastes entre lugares -visibles en los registros arqueológicos- podrían ser la única muestra viviente que se conserva actualmente de tal diversidad.

\section{5.- LAS OBRAS MONUMENTALES DEL «POBLADO ENIGMÁTICO» Y SU SIGNIFICADO}

Tras analizar la distribución del terreno intramuros que se desarrolló en Pendia, queremos plantear la duda de si una pequeña comunidad, como la que seguramente existió allí, pudo llevar a cabo por sí sola obras de este alcance o cuál es el fin que se persiguió con tamaño esfuerzo colectivo. Quizá para responder estas cuestiones debamos acudir al principio de monumentalidad desarrollado por Trigger (1990) ${ }^{8}$, según el cual se puede entender por mo-

\footnotetext{
${ }^{8}$ Es decir, según Trigger: «lts principal defining features is that its scale and elaboration exceed the requirements of any practical functions that a building is intended to perfom» (1990:119).
} 
numental toda obra que sobrepase de un modo destacado las necesidades esenciales de una comunidad humana. Es lo que Bradley llamó en su momento, las «innecesarias pirámides», ilustrando con un ejemplo clásico de la arqueología cómo detrás de esfuerzos constructivos desmesurados y, aparentemente, poco prácticos tuvo que haber siempre motivos significativos (1984: 72). Si estos grupos hicieron ese esfuerzo, y derivaron parte de su tiempo y de su trabajo hacia esas actividades, este ajuste ha de tener un fin y una explicación puesto que sino daríamos por sentado que estarían actuando al margen de los principios de supervivencia, algo que no es lógico concebir.

En nuestro caso, parece que el principio fundamental de esa teoría se respeta: la fortificación cumplió un fin, y debió ser importante en su momento. Además, ante el alcance de muchas obras, algunos autores han entendido los entramados defensivos desde un contexto local, con la comunidad como protagonista principal, pero incorporando también a quienes habitan el espacio próximo o circundante a la misma, sea en otros poblados o en caseríos dispersos ${ }^{9}$; al menos así se han leído recientemente las fortificaciones en el ámbito atlántico (RALSTON, 2007: 119). Por tanto, a la vista de la valoración espacial de las defensas (y del esfuerzo que debió generar su creación), quizá debamos aplicar al caso boalés una lectura muy semejante a la formulada por Ralston para la zona atlántica. Así, la participación de comunidades que viven en el entorno del poblado ${ }^{10}$ permitiría entender la manifiesta desproporción existente en Pendia entre los elementos defensivos o rituales (las saunas, por ejemplo) presentes y el escaso número de familias ${ }^{11} \mathrm{O}$ grupos que residen intramuros, sobre los que seguramente deberían recaer las tareas de construcción y mantenimiento. Quizá por esa razón sea necesario separarse del recinto fortificado y entender también el espacio que lo rodea que, aunque desconocido, desempeñó un papel esencial.

En consecuencia, la labor de refuerzo y apoyo de un colectivo más amplio de gente, muy probablemente procedente del entorno, parece muy necesaria para poder afrontar con éxito y en plazos razonables las tareas más duras, y quizá ese sea el único modo de que obras de ese calado se pudieran ir completando aunque fuese por tramos o sectores diferenciados. No parece que resulte anómalo este comportamiento solidario entre comunidades y grupos cercanos, puesto que muchas de las arquitecturas erigidas ya desde tiempos neolíticos necesitaron de la participación de conjuntos muy amplios de personas (DE BLAS, 2000: 216-219), agrupamiento que también permite explicar otras muchas actividades tan necesarias como exigentes: la apertura de espacios de cultivo, por ejemplo. Además, las mejoras y reformas de la muralla, que están bien constatadas en Pendia (RODRÍGUEZ Y VILLA, 2009), quedarían para períodos posteriores y también producirían una importante labor que en todo caso siempre sería más puntual. Pero esas reparaciones no son tampoco una rara avis ya que son bastante coherentes con el resto de casos conocidos en el continente, produciendo esa apariencia de obra inacabada (work in progress) que existe en otros cercados extrapeninsulares (RALSTON, 2007: 122).

Además, en nuestro caso de investigación, el lugar elegido para levantar las defensas hubo de incrementar la dificultad de todas y cada una de las tareas constructivas: desde el diseño, a la concepción y el trabajo sobre el terreno. Ese esfuerzo convertiría en todo un reto las obras allí ejecutadas ${ }^{12}$, mucho más cuando la sensación que transmiten algunas fortificaciones protohistóricas es desproporcionada. Resulta fácil de entender por tanto que excavar un foso de grandes dimensiones lleve aparejado un gasto de energía muy considerable, máxime en un lugar como Pendia en el que la construcción está cargada de dificultades. En el caso de los fosos hemos de tener en cuenta también otra cuestión: si los analizamos desde planteamientos puramente defensivos está documentado que no son necesarias trincheras muy profundas para crear perímetros que sean defendibles, concepto bien aprendido posteriormente por los romanos (GOLDSWORTHY, 2003: 89) ${ }^{13}$ y del que posiblemente tampoco fuesen del todo desconocedores los habitantes de los recintos fortificados. Por eso es posible que una fosa más profunda no asegure una mejor defensa, lo que podría indicar que hubo otros motivos, al margen de la funcionalidad y utilidad, para justificar que haya esas obras monumentales en superficies tan ingratas para construir. Entre ellas podría estar quizá el deseo de marcar el terreno y su posesión, fenómeno en el que el desarrollo de fortificaciones espectaculares pudo ser un refrendo palmario y un sello del colectivo que vive dentro o en los alrededores del poblado.

Al margen de la notoriedad defensiva la presencia de edificios vinculados a rituales, como dos saunas y una casa de asamblea, en un castro de pequeñas dimensiones, quizá no se deba explicar solo como elementos que sirven de marco a las relaciones externas con otros grupos o poblados, o como arquitectura en la que los habi-

\footnotetext{
9 Ya destacados hace tiempo en otros ámbitos (AUDOZE Y BUSCHENCHUTZ, 1989: 233), también se les ha empezado a dar importancia recientemente en el noroeste desde el Bronce Final (GONZÁLEZ, 2006-2007: 115-116), hasta la Edad del Hierro (CAMINO, 2002: 149) e incluso en tiempos posteriores.

${ }^{10}$ Bien en otros poblados, en caseríos dispersos del entorno de Pendia, o en una combinación de ambas posibilidades.

${ }_{11}$ Esta combinación ya fue documentada por Arenas Esteban en la zona del Alto Tajo-Alto Jalón, donde encontró «pequeñas fortalezas» que, como El Castellar de Berrueco, no son otra cosa que explotaciones de carácter familiar» (2011: 141).

12 Tal y como ya se ha señalado para el caso irlandés (RAFTERY, 1994: 44).

${ }_{13}$ Según este autor desde la época del Principado los romanos poseen los conocimientos técnicos para hacer defensas mayores pero no las hacen, lo cual no menoscabó la capacidad defensiva de los fuertes romanos.
} 
tantes desarrollan sus ceremonias intracomunitarias. Puede que en parte también esté inspirada por la evidente vinculación entre ese conjunto de personas y el territorio, relación que en momentos puntuales pudo requerir también de espacios de representación adecuada y que siempre encontraría una expresión más clara (y un mayor número de edificios), en aquellos castros anclados en puntos con una significación destacada en esa «geografía sagrada» que posiblemente existió en los tiempos prehistóricos (VILLA, 2008: 828-829).

\section{6.- CONSIDERACIONES FINALES}

Durante las etapas postreras de ocupación la muralla del castro de Pendia pasó a ser un mero elemento funcional dentro del poblado: sostén de nuevos edificios que crecen a su costa, freno a los rellenos de nuevas terrazas o plataforma para el firme de nuevas calles. Visto esto, y si admitimos que en época prerromana hemos cargado a las defensas con múltiples valores y connotaciones hemos de afrontar, tras la lectura de los registros, cómo y por qué ese pilar tan importante para el grupo de habitantes se desmorona y se ve alterado de una forma tan drástica en este y en otros casos conocidos. Llegados al punto en el que todo eso se trunca de forma súbita, la única explicación plausible con la información de la que disponemos es que se debe estar produciendo una intervención radical, que explique cambios tan repentinos y relevantes en dos de los elementos más emblemáticos del sitio, a saber: las murallas y las saunas. Y quizá aquí resulte esencial comprender el contexto social y político en que están viviendo estas comunidades. Mucho más cuando el radiocarbono ofrece en este sitio un margen demasiado amplio como para poder precisar: por eso, hemos de remarcar la entrada de una potencia como Roma en el territorio que debió suponer, al menos inicialmente, un cambio importante en los modelos de vida prerromanos, puesto que la ocupación de los castros llega a ser una realidad muy destacada (en el Chao Samartín, por ejemplo). De la misma forma a Pendia pudieron haber llegado algunos contingentes militares, si hacemos caso a la moneda aparecida en $2003^{14} \mathrm{o}$ a otros elementos que, no obstante, en la actualidad aún son de ambivalente y compleja clasificación ${ }^{15}$.

Además, los nuevos datos aportados parecen demostrar el interés de Roma en poner en marcha las minas de oro, fenómeno que pudo tener lugar en momentos mucho más tempranos de lo que se creía (VILLA, 2010: 105). Si las minas de la zona están funcionando en momentos inmediatos a la conquista romana eso implica que por el territorio ya han pasado las unidades militares y se encuentran de algún modo pacificados, lo cual no deja de ser un gran incentivo para el desarrollo de una serie de cambios importantes. Ante la posición de posibles campamentos romanos descubiertos recientemente en el concejo de Boal (MENÉNDEZ et alii, 2013: 248), no resulta extraño que el ejército frecuentase los castros próximos ya durante los períodos de las Guerras Astur-Cántabras, al menos de una forma esporádica. Aunque quizá no en todos tuvo por qué tener una presencia tan manifiesta como la documentada en los ejemplos más señeros, donde la alteración de las estructuras residenciales preexistentes llega incluso a imponer divisiones y particiones que recuerdan en gran medida a las formas campamentales (VILLA et alii, 2006).

Con la llegada de Roma a Pendia se alterarían muchos patrones constructivos en el castro, quizá un indicio de que la compleja red de relaciones sociopolíticas que había propiciado la construcción y quién sabe si el mantenimiento de las defensas centenarias se ha trastocado ya de un modo notable, adaptándose con seguridad a las pretensiones de los nuevos poderes. No olvidemos que este proceso no es exclusivo, ni mucho menos, del noroeste como bien demuestra la pérdida de valores que ocasiona la entrada de Roma en algunos territorios: recordemos que en la zona celtibérica, por ejemplo, produjo que la muralla nunca vuelva a ser el símbolo de identidad de las comunidades prerromanas, tal y como argumenta A. Jimeno (2011: 144). En el occidente de Asturias el Chao Samartín es el yacimiento paradigmático que nos proporciona un guión muy completo de este fenómeno, al que hay que sumar las remodelaciones de todos los edificios de baños de los castros del área occidental de Asturias. Las murallas de Pendia pueden sucumbir ante factores muy semejantes una vez que el territorio ya está conquistado, interpretación acorde con el terminus post quem de la muralla.

En suma, la intensa reforma del poblado de Pendia (RODRÍGUEZ, 2013; 2015-nota 2-), solo puede ser explicada dentro de una red compleja de fenómenos que podrían actuar de forma individual o conjunta: nuevas políticas, nuevas necesidades o imposiciones o, quizá, nuevos gustos podrían haber motivado sin duda los cambios. Como consecuencia se alteraron de forma significativa las morfologías urbanas preexistentes en este y otros poblados. De todas formas y al margen de quién lo haya llevado a cabo y por qué, el giro fue, en vista de los registros arqueológicos, muy efectivo pues supuso la caída de viejos símbolos comunitarios ante los impulsos de intensas reformas urbanas que en época romana dieron apariencia de aldea abierta a la gran mayoría de los fortines que, desde inicios de la Edad del Hierro, habían capitalizado la forma esencial de hábitat en este territorio.

\footnotetext{
${ }^{14}$ Ya se ha remarcado que el estado de conservación de este hallazgo impide una lectura nítida de la misma, por lo que la interpretación es la más plausible (GIL Y VILLA, 2006: 507).

${ }^{15}$ Hablamos del pequeño enganche de bronce interpretado inicialmente con enganche de tahalí, aunque bien podría ser también una sujeción de lorica similar a las ya aparecidas en el Chao Samartín (RODRíGUEZ Y VILLA, 2013: 213).
} 


\section{BIBLIOGRAFÍA}

ARENAS ESTEBAN, J. A.

2011 El poblamiento prerromano en el área del Alto Tajo-Alto Jalón, en ÁVAREZ-SANCHÍS, J., JIMENO MARTÍNEZ, A. Y RUIZ ZAPATERO, G. (Eds.) Aldeas y ciudades en el Primer Milenio a. C. La Meseta Norte y los orígenes del urbanismo. 129-146. Complutum 22 (2).

\section{AUDOZE, F. Y BUCHSENSCHUTZ. O.}

1989 Villes, villages et campagnes de l'Europe celtique: du début lle millénaire à la fin du le siècle avant J.C. Hachette. París.

BLAS CORTINA, M. A. de

2000 La Neolitización del litoral cantábrico en su expresión más consolidada: la presencia de los primeros túmulos, en $\mathrm{Ne}$ olitização e megalitismo da Península Ibérica. Actas do $3^{\circ}$ Congresso de Arqueologia Peninsular. 215-239. Vol. III. ADECAP. Porto

BRADLEY, R.

1984 The social fundations of prehistoric Britain. Themes and variations in the archeology of power. Longman Archaeology series. New York.

\section{CAMINO MAYOR, J.}

1995 Los castros marítimos en Asturias, Fuentes y estudios de Historia de Asturias. Real Instituto de Estudios Asturianos. Oviedo.

2000 Las murallas compartimentadas en los castros asturianos: bases para un debate. Archivo Español de Arqueología 73, 27-42.

2002 Algunos comentarios sobre las pautas territoriales y sociales de los castros del oriente de Asturias, en BLAS CORTINA M. A. DE Y A. VILLA (eds.). Los poblados fortificados del Noroeste de la Península Ibérica: formación y desarrollo de la cultura castreña. 139-158. Ayuntamiento de Navia-Parque Histórico del Navia. Navia.

\section{CUNLIFFE, B.}

2006 Understanding hillforts: have we progressed?, en The Wessex Hillfort Project. Extensive survey of hillforts interiors in central southern England. 151-163. English Heritage. London.

CHAPA BRUNET, T. Y MAYORAL HERRERA, V.

2007 Arqueología del trabajo. El ciclo de vida de un poblado ibérico. Akal Arqueología. Madrid.

EVANS, J. G. Y LIMBREY, S.

1974 The experimental earthwork on Morden Bog, Wareham, Dorset, England: 1963-1972. Proceedings of the Prehistoric Society 40, 170-203.

FERNÁNDEZ-POSSE, M. D. Y FERNÁNDEZ MANZANO, J

2000 Los recintos de los castros. La función social de la muraIla, en SÁNCHEZ-PALENCIA RAMOS, F. J. (coord.). Las Médulas (León): un paisaje cultural en la "Asturia Augustana". 82-91. Diputación de León, Instituto Leonés de Cultura. León.
GARCÍA Y BELLIDO, A.

1942 El castro de Pendia. Archivo Español de Arqueología 49 $(\mathrm{XV})$, 288-307.

GIL SENDINO, F. Y VILLA VALDÉS, A.

2006 La circulación monetaria en los castros asturianos, en GARCIA-BELLIDO, M. P. (coord.). Los campamentos romanos en Hispania (27 a. C.-192 d. C.). El abastecimiento de moneda. Anejos de Gladius 9(II), 501-519.

GOLDSWORTHY, A.

2003 El ejército romano. Akal. Madrid.

GONZÁLEZ RUIBAL, A.

2006-07 Galaicos: Poder y Comunidad en el Noroeste de la Península Ibérica (1200 a.C.- 50 d.C.), tomos I y II. Brigantium, 18-19.

2008 Los pueblos del Noroeste, en GARCíA ALONSO, F. (coord.). De Iberia a Hispania. 899-930. Ariel. Barcelona.

GRACIA ALONSO, F.

2006 Las fortificaciones ibéricas. Análisis poliorcético y concepto de su empleo táctico en la guerra de sitio, en OLIVER FOX, A. (coord.). Arquitectura defensiva. La protección de la población y del territorio en época ibérica. 63-122. Sociedad castellonense de cultura. Castellón de la Plana.

JIMENO MARTÍNEZ, A.

2011 Las ciudades celtibéricas de la Meseta oriental», en ÁLVAREZ-SANCHÍS, J., JIMENO MARTIINEZ, A. Y RUIZZAPATERO, G. (Eds.). Aldeas y ciudades en el Primer Milenio a. C. La Meseta Norte y los orígenes del urbanismo. 223-276. Complutum 22 (2).

MARTÍN BRAVO, A. M ${ }^{a}$

2004 Las casas y el urbanismo, en Celtas y Vettones. 122-133. Diputación de Ávila. Ávila.

MAYA GONZÁLEZ, J. L.

1988 La cultura material de los castros asturianos. Estudios de la Antigüedad 4/5. Universitat Autònoma de Barcelona. Bellaterra, Barcelona.

MENÉNDEZ BLANCO, A., GONZÁLEZ ÁLVAREZ, D., ÁLVAREZ MARTÍNEZ, V. Y JIMÉNEZ CHAPARRO, J. I.

2013 Campamentos romanos de campaña en el occidente de Asturias. Excavaciones arqueológicas en Asturias 7, 245-251.

OREJAS, A

1996 Estructura social y territorio. El impacto romano en la cuenca noroccidental del Duero. Anejos de Archivo Español de Arqueología XV. Universidad Complutense. Madrid.

PARCERO OUBIÑA, C.

2005 Variaciones en la función y el sentido de la fortificación a lo largo de la Edad del Hierro en el NO de la Península Ibérica, en BLANCO, A. CANCELO, C. Y ESPARZA, A. (eds.). Bronce Final y Edad del Hierro en la Península Ibérica. Encuentro de Jóvenes investigadores. 11-33. Fundación Duques de Soria-Universidad de Salamanca. 
RAFTERY, B.

1994 Pagan celtic Irland. The enigma of the Irish Iron Age. Thames and Hudson. London.

RALSTON, I.

2006 Celtic fortifications. Tempus. Gloucestershire.

2007 Celtic fortifications in the British Isles, en BERROCALRANGEL, L. Y MORET, P. (Eds.). Paisajes fortificados de la Edad del Hierro peninsular: las murallas protohistóricas de la Meseta y la vertiente Atlántica en su contexto europeo. 113-134. Real Academia de la Historia/Casa de Velazquez, Biblioteca Arqueológica Hispana.

\section{RODRÍGUEZ DEL CUETO, F.}

2012 Arquitecturas de barro y madera prerromanas en el occidente de Asturias: el castro de Pendia. Arqueología de la arquitectura 9, 83-101.

2013 Cambios y readaptaciones en la estructura urbana de un poblado fortificado: el caso del castro de Pendia (Boal). Munibe, Antropología-Arqueología 64, 129-143.

\section{RODRÍGUEZ DEL CUETO, F. Y VILLA VALDÉS, Á.}

2009 Excavaciones arqueológicas en el castro de Pendia (Boal). Excavaciones Arqueológicas en Asturias 6 (20032006), 159-170. Consejería de Cultura y Turismo. Oviedo.

2013 «Apuntes sobre el registro arqueológico en el castro de Pendia: contextos y artefactos». Excavaciones Arqueológicas en Asturias 7 (2007-2010), 207-220. Oviedo.

\section{RUIZ ZAPATERO, G. Y FERNÁNDEZ MARTÍNEZ V.M.}

1984 Patrones de asentamiento en el Bajo Aragón Prehistórico. Arqueología espacial 4, 43-63. Teruel.

\section{SÁNCHEZ PALENCIA, F.J. Y FERNÁNDEZ-POSSE, M. D.}

1985 La Corona y el castro de Corporales I. Truchas (León). Campañas de 1978 a 1981. Excavaciones arqueológicas en España 141. Madrid.

\section{SASTRE PRATS, I.}

2001 Las formaciones sociales rurales de la Asturia romana Ediciones clásicas. Madrid.

\section{TORRES MARTÍNEZ, J. F.}

2005 La economía de los celtas de la Hispania Atlántica II. Serie Keltia 28. Toxoutos. La Coruña.

\section{TRIGGER, B. G.}

1990 Monumental architecture: a thermodynamic explanation of symbolic behaviour. World Archaeology 22(2), 119-132.

\section{VILLA VALDÉS, A.}

1999 Plan Arqueológico Director de la Cuenca del Navia, en Excavaciones Arqueológicas en Asturias 4 (1995-1998. 205-211. Oviedo.

2002 Periodización y registro arqueológico en los castros del occidente de Asturias, en BLAS CORTINA M. A. DE Y A VILLA (eds.). Los poblados fortificados del Noroeste de la Península lbérica: formación y desarrollo de la cultura castreña. 159-188. Ayuntamiento de Navia-Parque Histórico del Navia. Navia.
2007 Intervención sobre los edificios termales en el castro de Pendia (Boal): reexcavación, lectura y consolidación con addenda judicial. Excavaciones Arqueológicas en Asturias 5, 283-294. Oviedo.

2008 Los castros en la geografía sagrada de Asturias: la pervivencia del mito, en La Prehistoria en Asturias. Un legado artístico único en el mundo. 826-832. Prensa Asturiana. Oviedo.

2008b Sobre el armamento, la guerra y la belicosidad de la sociedad castreña, en La Prehistoria en Asturias. Un legado artístico único en el mundo, 697-704. Prensa Asturiana. Oviedo.

2010 El oro en la Asturias Antigua: beneficio y manipulación de los metales preciosos en torno al cambio de era, en FERNANDEZ-TRESGUERRES, J.A. (coord.). Cobre y oro. Minería y metalurgia en la Asturias prehistórica y antigua. 83-125. Real Instituto de Estudios Asturianos. Oviedo.

2013 El castro de Coaña un poblado fortificado en los albores de la Historia de Asturias, en BLAS CORTINA, M.A. de (coord.). De Neandertales a Albiones: cuatro lugares esenciales en la Prehistoria de Asturias. 139-147. Real Instituto de Estudios Asturianos. Oviedo.

VILLA VALDÉS, A. Y CABO PÉREZ, L.

2003 Depósito funerario y recinto fortificado de la Edad del Bronce en el castro del Chao Samartín: argumentos para su datación. Trabajos de Prehistoria 60(2), 143-151.

VILLA VALDÉS, A., MENÉNDEZ GRANDA, A. Y GIL SENDINO, F.

2006 Fortificaciones romanas en el castro de Chao Samartín, en MORILLO, A. (Ed.). Arqueología militar romana en Hispania II : Producción y abastecimiento en el ámbito militar. 581-599. Universidad, Secretariado de Publicaciones. León. 